\title{
IOTFlood: Uma solução baseada em internet das coisas para monitoramento de enchentes de grandes proporções em tempo real
}

Francisco Vital S. Júnior ${ }^{1,2,}$ Mônica Ximenes C. Cunha1, Lucas Bryan Vieira²

${ }^{1}$ Programa de Pós-Graduação em Tecnologias Ambientais (PPGTEC) - Instituto Federal de Alagoas (IFAL) CEP 57.020-600 - Maceió - AL - Brasil

${ }^{2}$ Centro Universitário Tiradentes (UNIT - Maceió)

fcojunior3egmail.com, monicadifal.edu.br, lbryanlv@outlook.com

\begin{abstract}
In Alagoas, river monitoring is done with radar and level sensors that send information, via Radio and Satellite, every hour, about level and flow. However, a major flood can happen in minutes, hence the importance of a real-time monitoring system. This work presents IOTFlood, a hardware and software platform that generates alerts about possible natural disasters, sending messages in real time about the situation of rivers, as well as notifications and alerts to the population. It is an applied research using Design Science Research Methodology (DSRM). For evaluation, experiments were carried out in the laboratory and in a natural environment.
\end{abstract}

Resumo: Em Alagoas, o monitoramento dos rios é feito com sensores de radar e de nível que enviam informações, via Rádio e Satélite, a cada hora, sobre nivel e vazão. No entanto, uma enchente de grandes proporções pode acontecer em minutos, dai a importância de um sistema de monitoramento em tempo real. Este trabalho apresenta o IOTFlood, uma plataforma de hardware e software que gera alertas sobre possiveis desastres naturais, enviando mensagens em tempo real sobre situação dos rios, bem como notificações e alertas à população. Trata-se de uma pesquisa aplicada, que utilizou Design Science Research Methodology (DSRM). Para avaliação, foram realizados experimentos em laboratório e em ambiente natural.

\section{Introdução}

O Brasil, considerado um país de dimensões continentais, apresenta diferentes condições climáticas, ao longo de sua extensão, bem como distintos problemas relacionados ao excesso ou escassez hídrica. Atualmente o maior problema tem sido a escassez da qualidade hídrica (MACHADO; TORRES, 2012), pois mesmo nos lugares onde a quantidade de água é abundante para diversos usos, a qualidade ainda se mostra insuficiente para os padrões de consumo.

Uma tecnologia que tem sido utilizada para minimizar os impactos desses desastres é o Sensoriamento Remoto, que é definida como um conjunto de "hardwares" e "softwares" utilizados na coleta e tratamento de informações espectrais obtidas à distância, de alvos na superfície terrestre (RODRIGUEZ, 2005).

A evolução da engenharia de sensores associada à tecnologia de informação e serviços de telecomunicações surgiu para auxiliar na criação de projetos de baixo custo 
de implantação e manutenção. A revolução da Internet das Coisas (IoT - Internet of Things) tornou-se uma realidade e refere-se ao uso de sensores, atuadores e tecnologia de comunicação de dados montados em objetos físicos, de autoestrada a marca-passo, que permitem que os objetos (ou coisas) sejam monitorados, coordenados ou controlados através de uma rede de dados ou da Internet (PRADO, 2014).

As tecnologias ambientais são igualmente utilizadas para recolher informações sobre o ambiente, acompanhamento e recolhimento de dados para identificar a presença de poluentes, alterações na ocupação dos solos ou para detectar os efeitos na saúde humana através da biomonitorização. O setor da água, por sua vez, enfrenta o desafio de desenvolver tecnologias novas e mais econômicas que incluam os aspectos energéticos e as externalidades ambientais.

Nos rios do Estado de Alagoas existem 26 pontos nas estações hidrometeorológicas que fazem o monitoramento com sensores de radar e sensores de nível que enviam via GPRS e Satélite informações de hora em hora sobre nível e vazão, onde as mesmas são visualizadas em um monitor com dados sobre a intensidade de subida. No entanto, uma enchente de grandes proporções pode acontecer em minutos, daí a importância de um sistema de monitoramento em tempo real. Diante desta lacuna, entende-se que as tecnologias e inovações ambientais que utilizam sensores digitais, integrando hardware e software, podem ser inseridas no cenário de monitoramento dos rios alagoanos de forma a gerar dados instantâneos auxiliando a tomada de decisão da Secretaria de Meio Ambiente e Recursos Hídricos (SEMARH) quanto a possibilidade de ocorrência de enchentes.

Nesse contexto, este trabalho apresenta o IotFlood, um sistema para monitoramento de enchentes, composto por sensores de superfície que coletam dados de pressão atmosférica, nível de elevação do rio, ocorrência de chuva, elevação dos rios, temperatura e localização. Para isso, foi utilizado um microcontrolador com baixo consumo de energia para efetuar as leituras dos dados dos sensores e transmiti-los via LoRaWAN para um gateway remoto, conectado à Internet, que repassa os dados recebidos para um servidor na nuvem. Essa estação, além de possuir uma arquitetura aberta de implementação, com uma solução integrada de software e hardware de baixo custo, tem como diferenciais: (i) possibilidade de instalação em locais remotos e sem acesso à Internet ou sinal de celular; (ii) longo alcance de transmissão (podendo chegar a dezenas de quilômetros); (iii) acesso aos dados pela Internet; (iv) criação de gráficos mostrando a variação dos dados, com possibilidade de geração de alarmes para notificar situações que necessitam de atenção, tornando possível tomar ações preventivas; (v) fácil instalação e utilização; e (vi) longa autonomia de bateria, dispensando a necessidade de bancos de bateria para atingir essa longevidade.

\section{Trabalhos Relacionados}

A pesquisa de Helal (2018) descreveu a construção um protótipo, denominado EstAcqua, de uma estação ambiental e oceanográfica com sensores de superfície e submersos de baixo custo, com hardware de baixo custo, utilizando transmissão de dados sem fio via LoRaWAN e software aberto com baixo consumo de energia e longo alcance de transmissão. A EstAcqua possui sensores de iluminância, pressão atmosférica, umidade, temperatura externa e subaquática. A IotFlood se diferencia por ser aplicado ao monitoramento de enchentes em lagoas e rios, tendo como referência os sensores de nível, de localização (GPS), de chuva, ultrassônico, temperatura e pressão. 
Em seu trabalho, Junior e Schimiguel (2019) relataram a criação de um sistema de irrigação inteligente e sustentável chamado "Less Water", utilizando painéis solares como fonte energia renovável e sendo automatizado para auxiliar no cultivo de hortaliças, permitindo gerenciar e monitorar a temperatura do ar, umidade do solo e do ar. A IotFlood se diferencia por usar LoRaWAN para transmissão dos dados e ser focado em monitoramento ambiental e dos rios.

Já no trabalho de Tzortzakis et al. (2017), foram utilizados Microcontroladores Atmega328 com placa de transmissão sem o LoRa para coletar dados ambientais em cidades e transmiti-los via LoRa para um gateway, que por sua vez encaminha os dados para um servidor IoT utilizando GPRS. Os dispositivos que coletavam os dados eram energizados através de bateria e placa solar. A IotFlood se diferencia pela utilização de nós expostos ao ambiente, transmissão de dados próximos ao chão e utilização de LoRaWAN no envio dos dados coletados.

Como é possível observar nos trabalhos supracitados, geralmente as soluções são para curto alcance, dependentes de um computador próximo para se obter os dados dos sensores ou de uma fonte de energia externa para energizar o equipamento. Dessa forma, um diferencial da arquitetura proposta neste trabalho é a sua aderência a IoT, onde os dados dos sensores podem ser acessados através de uma interface Web ou de um celular, sem a necessidade de infraestrutura existente no local de instalação da IoTFlood. Utilizando hardware de baixo custo, software de código aberto e serviços online gratuitos para a visualização dos dados coletados.

\section{Metodologia}

O presente trabalho trata-se de uma pesquisa aplicada, pois objetiva gerar conhecimentos para aplicação prática dirigida à solução de problemas. Para isso, foi adotado o Design Science Research Methodology (DSRM), proposto por Peffers (2007), como procedimento metodológico da pesquisa para o desenvolvimento de artefatos de hardware e software.

A Design Science Research tem como objetivo estudar, pesquisar e investigar o artificial e seu comportamento, tanto do ponto de vista acadêmico quanto da organização (BAYAZIT, 2004). O modelo de processos da DSMR consiste em seis etapas: 1. Identificação do problema e motivação; 2. Definição dos objetivos para a solução; 3 . Concepção e desenvolvimento; 4. Demonstração; 5. Avaliação; 6. Comunicação. O quadro 1, por sua vez, apresenta a descrição das seis etapas supracitadas, devidamente adaptadas ao propósito da presente pesquisa.

\begin{tabular}{|c|l|}
\hline Diretriz & \multicolumn{1}{c|}{ Aplicação da Diretriz } \\
\hline $\begin{array}{c}\text { Identificação do } \\
\text { Problema } \\
\text { e Motivação }\end{array}$ & $\begin{array}{l}\text { O problema desta pesquisa está voltado à necessidade da deteção de } \\
\text { enchentes em tempo real. Gerar dados sobre os níveis dos rios em tempo } \\
\text { real e manter os mesmos para tomada de decisão é um grande desafio. }\end{array}$ \\
\hline \multirow{5}{*}{ Definição dos Objetivos } & $\begin{array}{l}\text { Pesquisar e analisar as tecnologias de monitoramento dos rios baseados } \\
\text { em internet das coisas usando sensores citadas na literatura; } \\
\text { Implementar uma arquitetura de hardware e software que suporte os } \\
\text { serviços oferecidos mais adequados ao projeto; } \\
\text { Desenvolver uma Versão "Beta", uma versão "candidata" e uma versão } \\
\text { "estabilizada" da solução com Internet das Coisas (IOT); } \\
\text { Realizar testes do artefato em laboratório e em campo. }\end{array}$ \\
\hline $\begin{array}{c}\text { Concepção e } \\
\text { Desenvolvimento } \\
\text { (O artefato) }\end{array}$ & $\begin{array}{l}\text { O artefato resultante desta pesquisa consiste em um produto baseado em } \\
\text { hardware e software que alinhado à tecnologia de Internet das Coisas } \\
\text { proporciona tomadas de decisões ágeis no contexto de enchentes de } \\
\text { grandes proporçôes, beneficiando a população civil. }\end{array}$ \\
\hline
\end{tabular}




\begin{tabular}{|c|c|}
\hline Demonstração & $\begin{array}{l}\text { Simulação do ambiente real em uma maquete montada dentro de um } \\
\text { aquário no laboratório, onde foram realizadas diversas simulações dos } \\
\text { contextos de enchentes, inundações e alagamentos com variações da } \\
\text { intensidade das chuvas e períodos de horas distintos. } \\
\text { Testes em ambiente real em campo, na cidade de União dos Palmares, } \\
\text { no Rio Mundaú que possui histórico de enchentes. Os testes atenderam } \\
\text { aos requisitos da pesquisa. } \\
\text { Verificação dos dados gerados no sistema de alertas contra desastres } \\
\text { naturais com IOT enviando dados para plataformas web e mobile em } \\
\text { tempo real sobre situação dos rios, onde os testes foram realizados tanto } \\
\text { em laboratório como em campo. }\end{array}$ \\
\hline Avaliação & $\begin{array}{l}\text { Foram realizadas avaliações de usabilidade, dados gerados e } \\
\text { comunicação entre os sensores, com o envolvimento dos usuários } \\
\text { utilizando a análise de observação de uso e a análise de utilização de } \\
\text { componentes (logs e interfaces). }\end{array}$ \\
\hline $\begin{array}{c}\text { Comunicação da } \\
\text { Pesquisa }\end{array}$ & $\begin{array}{l}\text { Publicação de artigos sobre a pesquisa. } \\
\text { Visa a comunidade científica interessada no desenvolvimento, pesquisa } \\
\text { e inovação de projetos nessa linha de Internet das Coisas (IoT) com } \\
\text { aplicabilidade em cenários relacionados. } \\
\text { Registro no INPI como Programa de Computador ou Patente de } \\
\text { Software, tendo o software embarcado em um hardware, essencial ao } \\
\text { funcionamento deste, onde o mesmo pode ser patenteado por atender os } \\
\text { requisitos de novidade, invenção e aplicação industrial. }\end{array}$ \\
\hline
\end{tabular}

\section{Quadro 1 - Etapas do DSRM adaptadas para a pesquisa.}

\section{IOTFlood: Concepção, Desenvolvimento e Validação}

Para o ambiente de teste em laboratório, foi planejado e construído uma espécie de "aquário" ou "maquete", em estrutura de vidro, com as dimensões de $100 \mathrm{~cm} \times 50 \mathrm{~cm} \times 70 \mathrm{~cm}$, com o intuito de simular uma situação de leito e margem de um rio, com o declínio usual, cuja representação gráfica está representada na Figura 1. Os elementos utilizados foram: torneiras (1), sensores de nível (2), medidor de vazão (3), caixa nó de sensores (4), sensor ultrassônico (5), sensor de chuva (6), chuveiro (7), gateway (8), servidor de rede TTN (9), aplicações web e mobile (10).

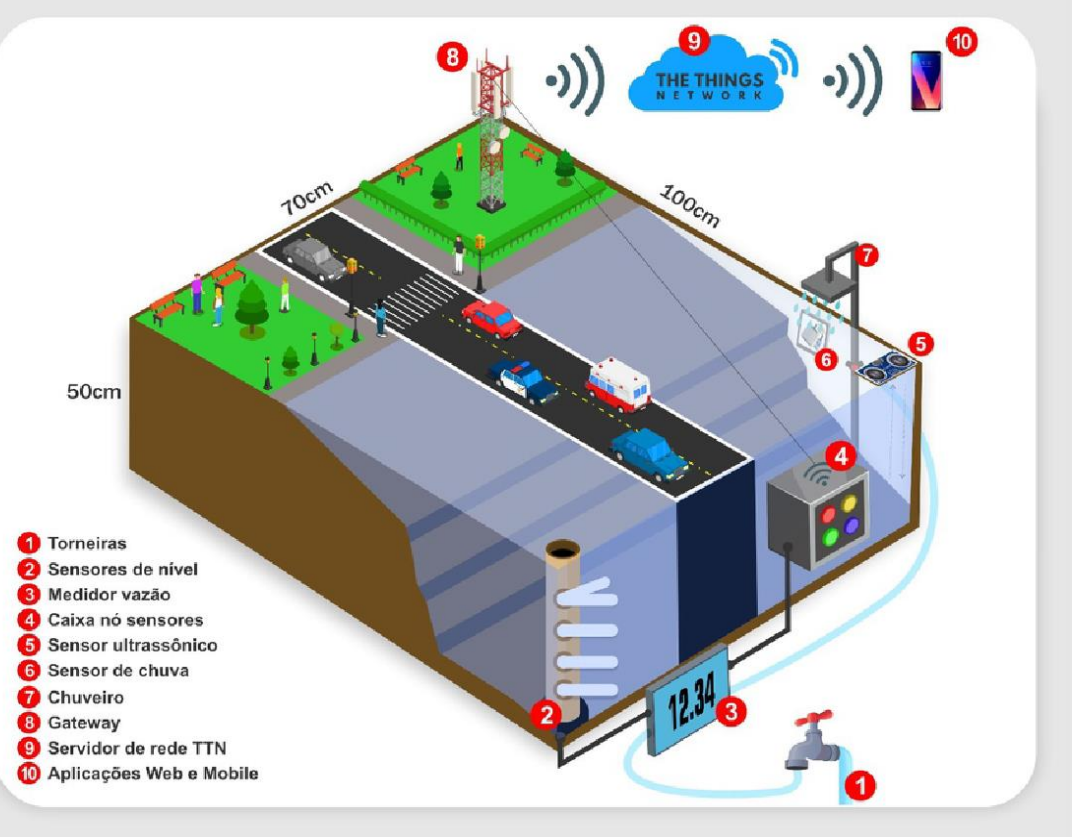

Figura 1 - Representação gráfica da maquete do laboratório. 
O principal desafio deste projeto foi realizar as leituras dos sensores supracitados. Para isso, foi necessário a modelagem de circuitos auxiliares para fazer a interface entre o sensor e o microcontrolador, cujo diagrama está descrito na Figura 2. Os sensores utilizados possuem dois valores diferentes de tensão de alimentação: 3,3 e 5 volts; necessitando, assim, de um regulador de tensão. O sensor ultrassônico, por sua vez, envia o sinal digital de 5 volts através do pino ECHO, entretanto, o microcontrolador utilizado trabalha com nível de tensão em 3,3 volts, necessitando assim de um divisor de tensão formado por resistores com o intuito de não danificar a sua entrada digital.

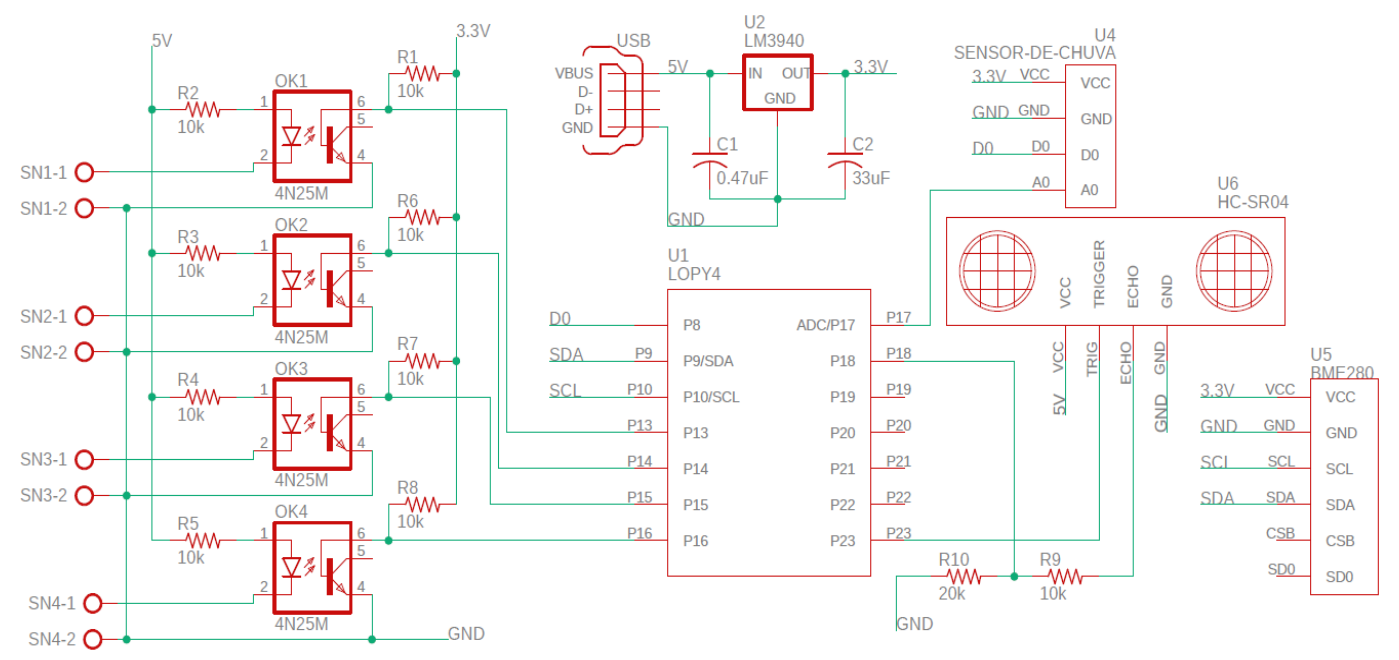

Figura 2 - Diagrama elétrico da placa de campo.

Além disso, o sensor de nível - tipo bóia - também necessitou de um circuito para isolar a alimentação dos contatos da chave (on/off) para proteger o microcontrolador de picos de corrente realizados pela comutação das chaves de nível, que no caso do sensor ultrassônico era para proteção contra tensões acima de 3,3 volts. Para as chaves de nível, foi utilizado um conjunto de opto-acopladores, que são componentes que isolam circuitos eletronicamente através de um led infravermelho e, por sua vez, realiza o envio do sinal sem o risco de picos de corrente que danifiquem os componentes. Para esta pesquisa, os sensores de chuva e bme280 não necessitaram de nenhum circuito integrado auxiliar pois já possuíam uma interface que os alimentavam através de 3,3 volts.

Para auxiliar a conexão dos sensores foram criados dois circuitos independentes por meio de Placas de Circuito Impresso (PCI). A placa do ambiente do campo é mais compacta, uma vez que necessita apenas realizar as leituras de nível (analógico e digital), temperatura, pressão, indicação da chuva e intensidade da mesma. Por sua vez, a placa do laboratório realiza as mesmas medições do ambiente em campo, entretanto é empregado sinalização visual através de LEDs que necessitam de acionamento por relés em tensão alternada. Ambas estão representadas na Figura 3. 


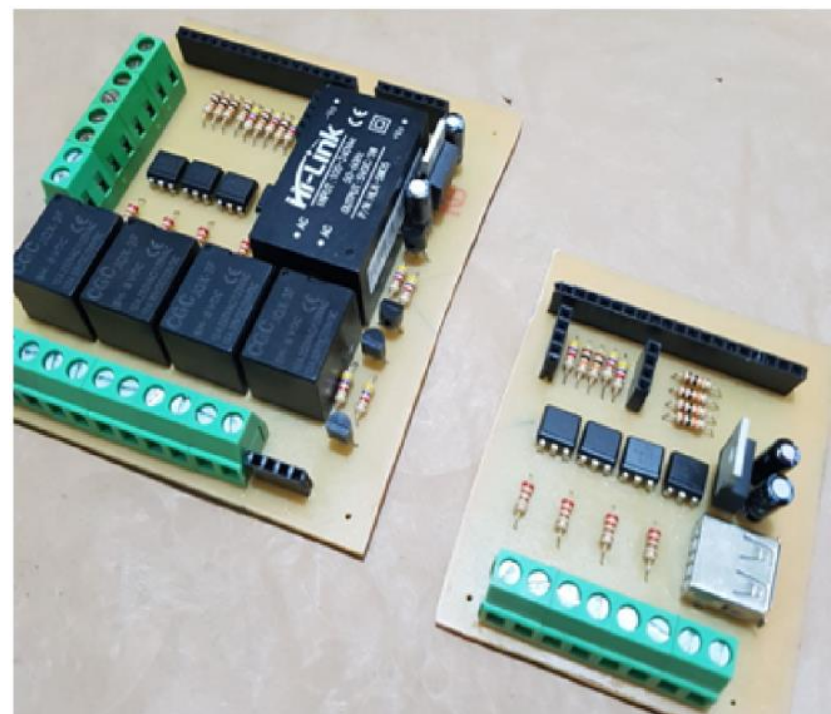

Figura 3 - Placas auxiliares da Expansion Board (laboratório e campo).

O desenvolvimento do software do projeto IOTFlood foi baseado nos princípios do modelo Iterativo Incremental, que contribui na redução de erros, falhas e defeitos encontrados pelo usuário final após entrega das solicitações.

O software utilizado no nanogateway foi uma modificação realizada pelo pesquisador a partir da versão oficial disponibilizada pela Pycom. É composto por três algoritmos - um distinto e dois semelhantes - que regem o funcionamento do nanogateway para o tratamento dos dados recebidos e encaminhamento para a TTN, e outros dois semelhantes para os nodes (ambiente e laboratório) que realizam a leitura das informações através dos sensores e empacotam para o nanogateway, diferem apenas por um circuito auxiliar de acionamento para relés na placa desenvolvida para o laboratório, acionando assim sinaleiras leds de tensão alternada.

Após a instalação e inicialização do nó, ele entra no modo ativo, que dura aproximadamente $3,5 \mathrm{~s}$, onde (i) realiza as medições; (ii) compacta os dados para a criação de um pacote no formato Cayenne LPP3; (iii) envia o pacote para o nanogateway; (iv) e entra em modo deep sleep, onde permanece por 10 segundos. Após esse tempo ele acorda novamente e repete o processo, enviando para a TTN as informações para disponibilização online, tanto via web ou através do celular usando o aplicativo Cayenne. A arquitetura do IOTFlood é dividida em quatro partes: um ou mais nós transmissores de dados, um receptor de dados, uma nuvem de Internet das Coisas (IoT Cloud) e a interação com usuário. A Figuras 4 ilustra o ambiente de laboratório, onde é possível identificar o nó conectado aos sensores, como também a integração entre servidores de gateway, de identidade, de rede, de aplicação e as camadas de aplicação para o IOTFLOOD.

Os dados lidos dos sensores são empacotados e transmitidos para o nanogateway. Este, por sua vez, ao receber os dados enviados pelo nó, os encaminha para a nuvem IoT, nesse caso a TTN. E com a integração da TTN com o Cayenne, esse dado chega até o servidor de aplicação, onde é disponibilizado para o usuário. A arquitetura do ambiente de laboratório é alimentada com 220 volts e possui leds de iluminação em cada nível de enchentes, enquanto que a arquitetura do ambiente real é alimentada com 5 volts e não possui leds de iluminação, visto que os leds encontrados no mercado só funcionam com 220 volts. 


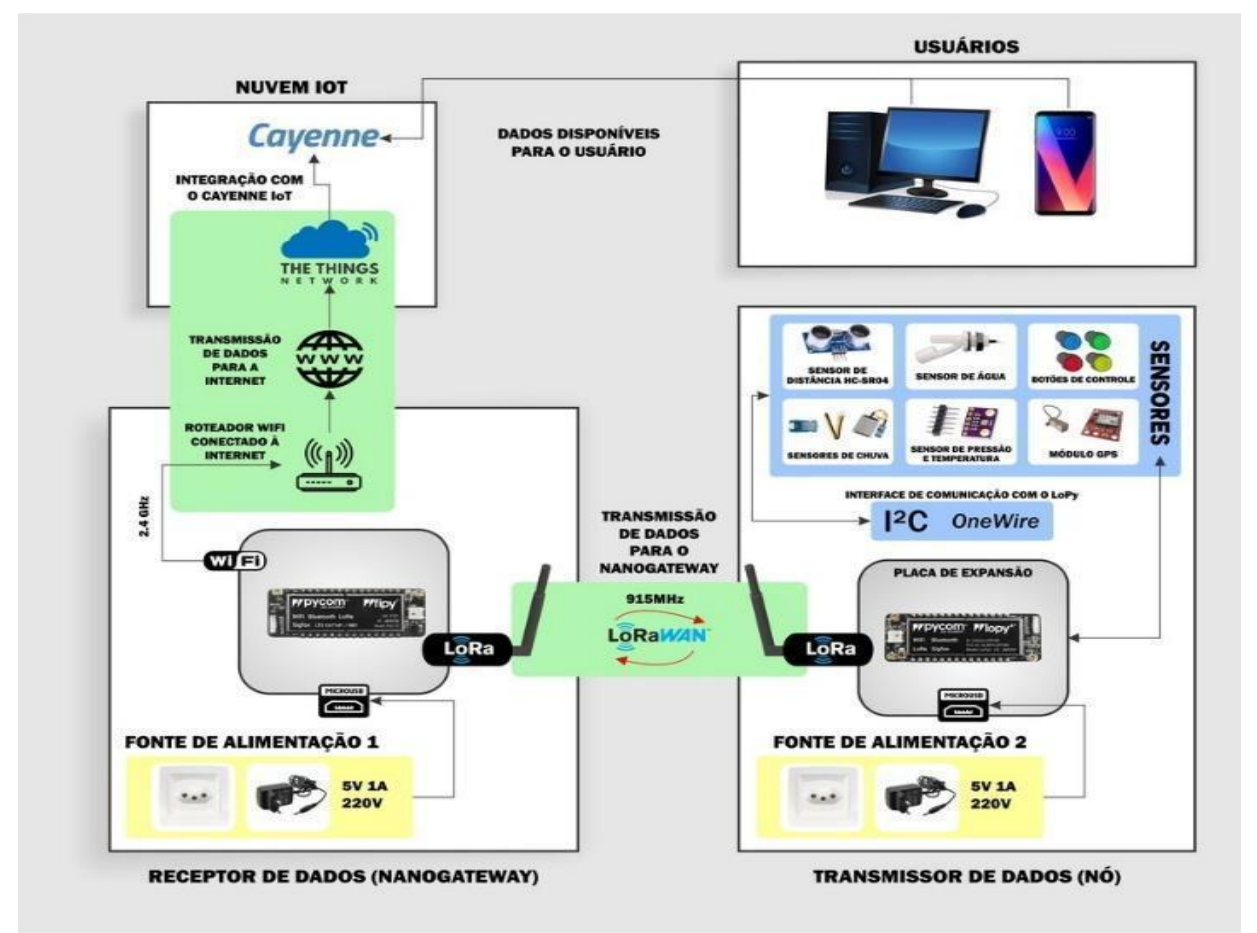

Figura 4 - Arquitetura do Ambiente em Laboratório.

O investimento inicial para realizar diversos testes com componentes distintos até chegar ao melhor conjunto pode ser considerado alto, sem considerar o valor das horas de trabalho dos envolvidos. Mas, após identificar a melhor opção de componentes para construção dos artefatos, é possível dizer que os custos totais para se ter um nanogateway e um nó no modelo da arquitetura proposta podem ser considerados acessíveis, chegando ao valor de $\$ 300,00$ (trezentos dólares) ou cerca de $\mathrm{R} \$ 1.500,00$ (hum mil e quinhentos reais), conforme descrito na figura 6 .

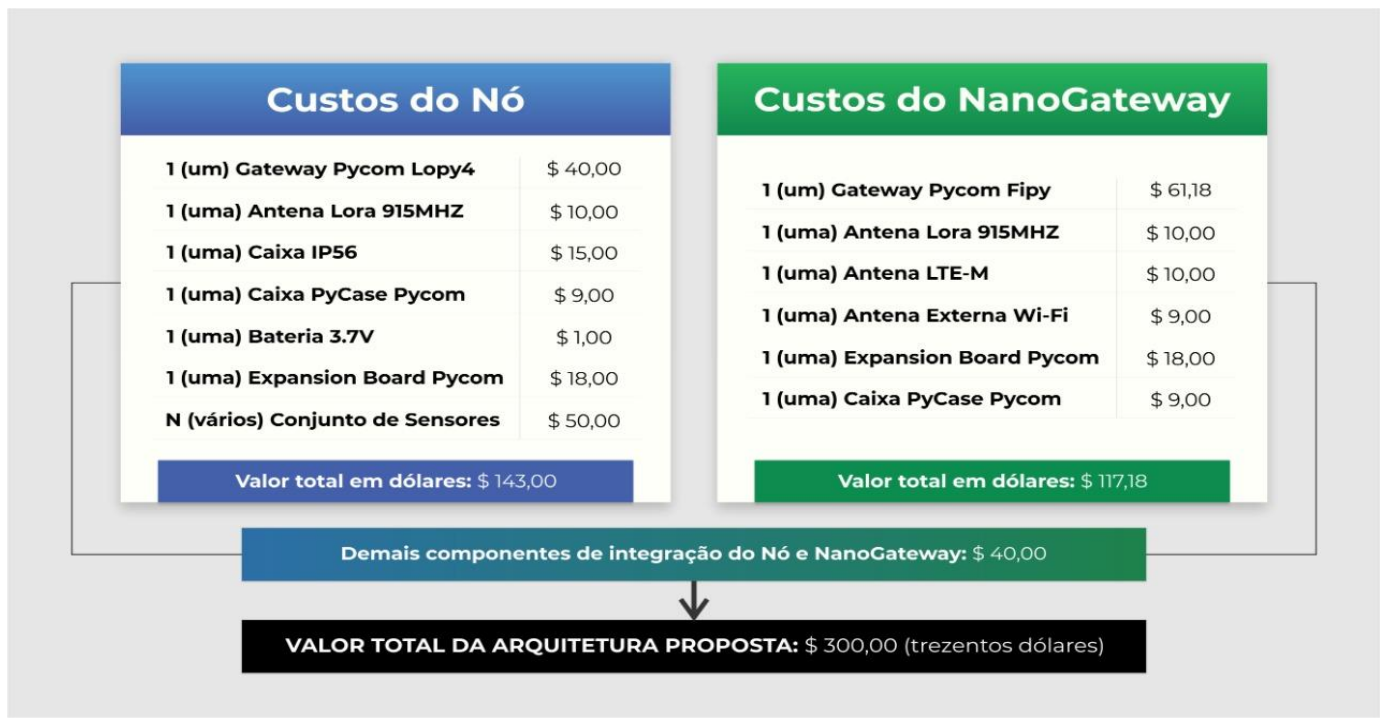

Figura 6 - Relação de custos dos itens utilizados para compor o hardware do IOTFlood.

\section{Validação do IOTFLOOD}

É importante ressaltar que os testes realizados possuíram o intuito de mostrar que a modularidade do IOTFlood permite que diferentes configurações de sensores podem ser acopladas a IOTFlood. Para avaliar as funcionalidades e atendimento aos requisitos do processo de coleta, transmissão e processamento dos dados do protótipo, foram 
realizados os seguintes testes: (i) avaliação no laboratório, visando analisar o comportamento do protótipo em local com variáveis controladas para simulação do ambiente real; (ii) avaliação no Rio Mundaú, visando analisar o comportamento do protótipo em ambiente real no campo.

Os testes de laboratório envolveram monitoramento da pressão, umidade, temperatura, níveis da enchente e geolocalização. Os dados foram enviados para o nanogateway localizado a 10 metros de distância do nó, estando conectado à rede sem fio no laboratório. $\mathrm{O}$ nó foi acoplado juntamente com todos os sensores em uma caixa elétrica padrão do modelo bifásica e trifásica, conforme representado na figura 7 , que também mostra como os dados são disponibilizados de forma online para o usuário, versões web e mobile, respectivamente.

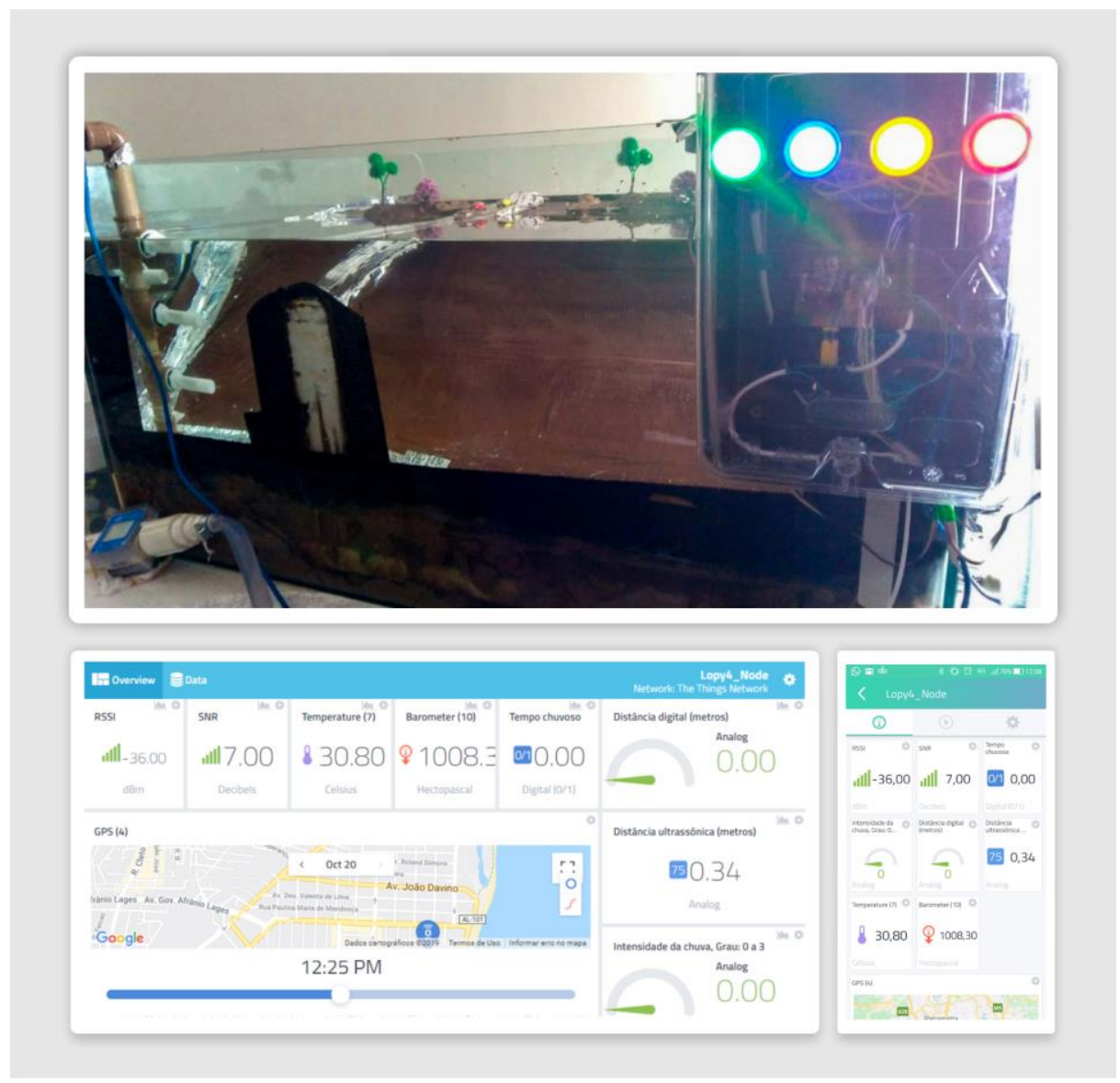

Figura 7. Ambiente laboratório com sensores acoplados, cenário inundação, com os respectivos dashboards web e mobile.

A figura 8, por sua vez, apresenta os gráficos dos sensores durante os testes em processo de validação no laboratório. Cabe destacar que o sensor de distância analógica (nível) captou as simulações da elevação do rio, a partir da adição e retirada de água, sinalizadas nos pontos B, C, D e E. Por sua vez, o sensor ultrassônico de distância captou as variações advindas das simulações de elevação do rio, conforme percebe-se na diversidade de elevações e baixas de nível (pontos G, H, I, K e L), com água adicionada por meio de um chuveiro. É possível perceber que o sensor de intensidade de chuva captou a adição e retirada de água do "aquário" de teste, retratada nos pontos $\mathrm{M}, \mathrm{N}, \mathrm{O}, \mathrm{P}$, Q e R. O sensor de tempo chuvoso, instalado abaixo do chuveiro, detectou as simulações de tempo sem chuva e após chuvas de leve a intensas, observadas nos pontos $\mathrm{S}, \mathrm{T}, \mathrm{U}, \mathrm{V}$ e X. 

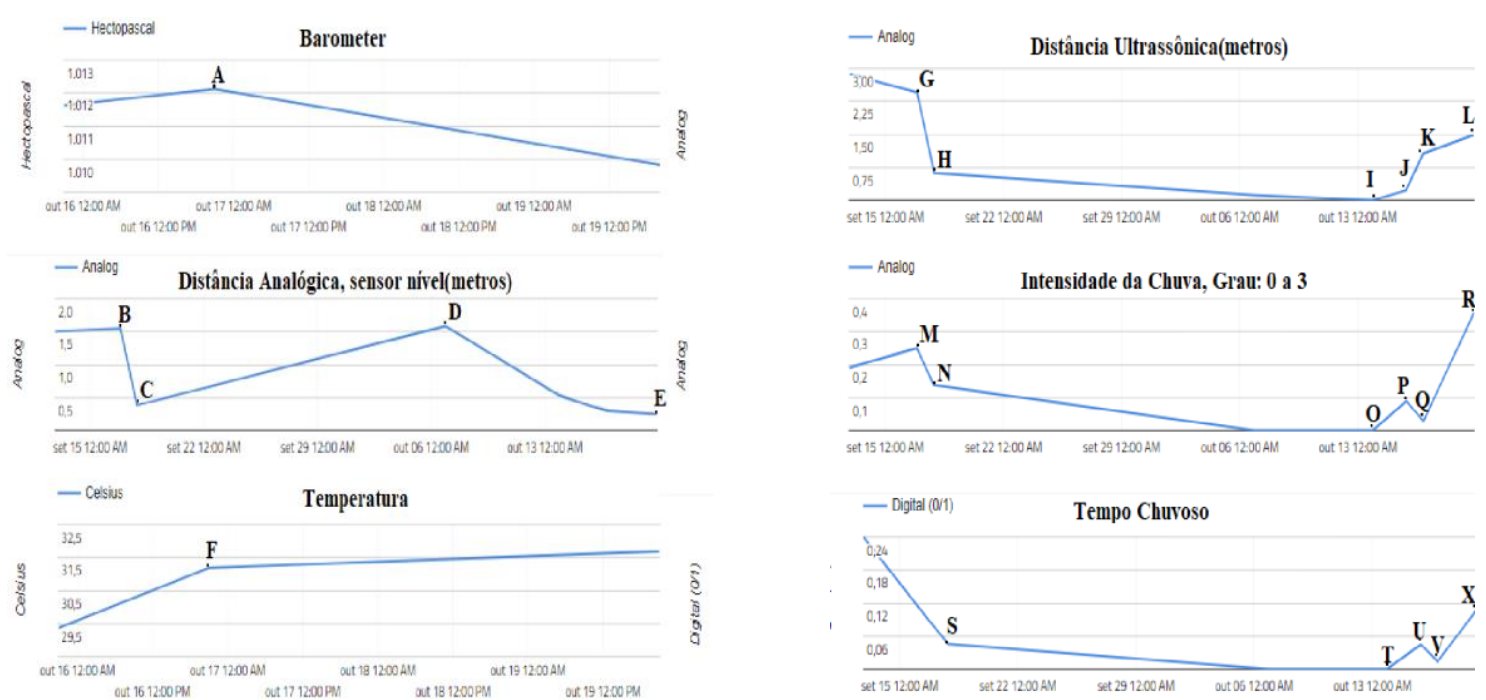

Figura 8 - Gráficos dos sensores de pressão, sensor de nível, temperatura, distância ultrassônica, intensidade de chuva e indicador de tempo chuvoso obtidos nos testes de laboratório.

Os testes de monitoramento e comunicação para validação no ambiente real em campo foram realizados na cidade de União dos Palmares - AL, que já passou por enchentes de grandes proporções e por este motivo foi escolhida para realização dos testes, monitorando a pressão, umidade, temperatura, níveis da enchente e geolocalização. Os dados foram enviados para o nanogateway localizado a 15 metros de distância do nó, estando conectado à rede sem fio do celular do pesquisador. $\mathrm{O}$ nó foi acoplado com todos os sensores em uma caixa elétrica padrão do modelo bifásica e trifásica e fixado na base da ponte do rio, conforme ilustrado na Figura 9.

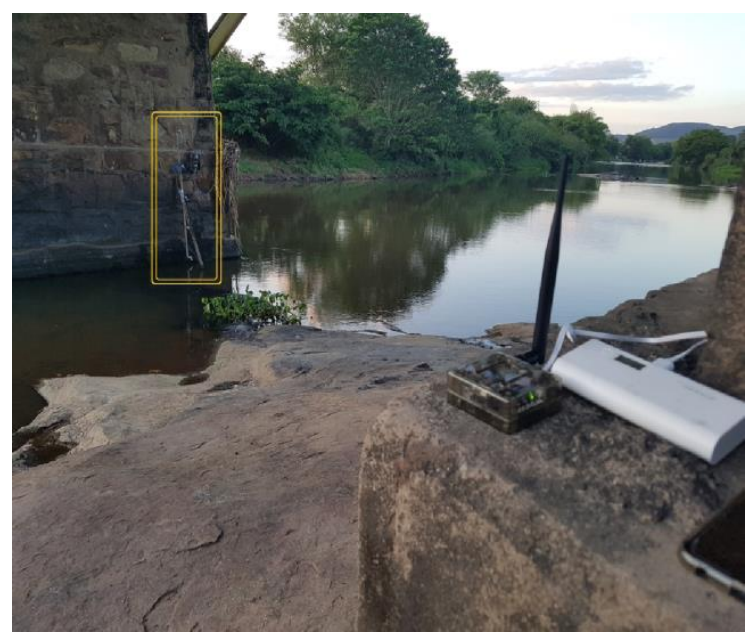

Figura 9 - Testes de Campo - visão do Nó (ao fundo) e NanoGateway (à frente).

Além dos dados captados pelos sensores descritos para o cenário de laboratório, é possível configurar a aplicação Cayenne para o envio de mensagens específicas de alertas por email ou pelo Serviço de mensagens curtas (SMS) de acordo com o monitoramento dos valores de cada sensor, tendo assim melhor eficácia na análise para tomada de decisão em casos de enchentes de pequena, média e grande proporção. 


\section{Conclusão}

Este trabalho apresentou o processo de construção do IOTFlood, uma estação com sensores de superfície para monitoramento ambiental do nível dos rios em tempo real, com alta autonomia de bateria e longo alcance de transmissão. Os dados coletados pelo IOTFlood são transmitidos para um servidor de Internet das Coisas na nuvem, onde são repassados para uma aplicação, possibilitando que o usuário tenha acesso aos mesmos.

Os testes realizados mostraram que a tecnologia LoRa atende perfeitamente os propósitos do IOTFlood, conseguindo transmitir dados para um gateway situado a até 1,5 $\mathrm{km}$ de distância. Os testes realizados no ambiente de laboratório e no campo geraram dados e gráficos suficientes que mostram a eficiência do IOTFlood. O servidor de Internet das Coisas na nuvem possibilitou a criação de gráficos para visualização dos dados coletados, disponibilizando tanto via web quanto mobile, além de permitir a criação de alarmes para alertar a ocorrência de situações anômalas.

Como sugestões para trabalhos futuros registra-se a possibilidades de explorar a validade dessas conclusões em ambientes distintos, em diferentes pontos do rio, com variação da intensidade de vento, correnteza, nível de água. Além disso, um estudo para a inclusão de novos sensores para monitoramento de líquidos e integração com aparelhos que necessitam de automatização também pode ser realizado.

\section{Referências}

Bayazit, N. (2004). Investigating Design: A Review of Forty Years of Design Research, Massachusetts Institute of Technology. Design Issues, v. 20, n. 1, p. 16- 29.

Helal, A. A. et al. (2018). Estacqua: Proposta de solução integrada de hardware, software e Internet das coisas para monitoramento ambiental. In: Sociedade Brasileira de Computação OPEN LIB. Natal: [s.n.]. ISSN 2595-6205. Disponível em: https://sol.sbc.org.br/index.php/semish/article/view/3432.

Junior, J. C. O., Schimiguel, J. (2019). Implementando uma plataforma big data para visualização de dados gerados por dispositivo IOT. Disponível em: http://www.portal.anchieta.br/revistas-e-livros/ubiquidade/pdf/2019/artigoubiquidade-vol2-num2-artigo5.pdf. Acessado em 29/04/2020.

Machado, P. J. O., Torres, F. T. P. (2012). Introdução à Hidrogeografia: Série Textos Básicos de Geografia. São Paulo: Cengage Learning.

Peffers, K. et al. (2007). A design science research methodology for information systems research. Journal of Management Information Systems. Doi: 10.2753/MIS 07421222240302 , v. 24 , n. 3 , p. $45-77$.

Prado, E. (2014). Internet das Coisas: O charme dos sensores. Disponível em: https:/www.convergenciadigital.com.br/cgi/cgilua.exe/sys/start.htm?UserActiveTe mplate $=$ site $\&$ infoid $=38222 \&$ sid $=15$. Acesso em: 07/03/2019.

Rodriguez, A. C. M. (2005) Sensoriamento Remoto e Geoprocessamento aplicados na Análise da Legislação Ambiental no Município de São Sebastião (SP). 217 p. Dissertação (Pós-Graduação em Geografia Humana) - Universidade de São Paulo.

Tzortzakis, K. et al. (2017) Wireless self-powered environmental monitoring system for smart cities based on lora. In: Panhellenic Conference on Electronics and Telecommunications (PACET). IEEE Transactions on Instrumentation and Measurement. Disponível em: https://ieeexplore:ieee:org/document/8259970. 